\title{
PETROPHYSICS OF KIMBERLITES
}

\author{
By Frank Arnott ${ }^{1}$, Eddie Kostlin ${ }^{2}$ \\ ${ }^{1}$ Arnott Geophysical Consulting, UK; ${ }^{2}$ Consulting Geophysicist, South Africa
}

\section{INTRODUCTION}

Geophysical exploration technology has made significant advances in recent years. Of particular benefit to diamond exploration are, improved resolution, rapid detailed coverage for traditional methods such as air gravity gradiometers and electromagnetics, multiple parameter 3D surveys and 3D computer modeling are all now feasible. This has taken geophysics from being an anomaly detection process to one capable of accurate mapping of kimberlites and lamproites. However to be effective, consistent knowledge is required concerning the relationships between geological, geochemical and petrophysical observations.

This paper provides a summary of what is known about the petrophysics of kimberlites as a basis to future work. It includes some examples of detailed investigations into geological explanations for the observed variations. Through appropriate investigations, geophysics has an ever increasing role to play in the evaluation of the economic potential of kimberlitic intrusives and understanding their origins.

\section{KIMBERLITE GEOPHYSICAL FACIES}

The subdivisions within kimberlites are broadly based on the mode of emplacement. These facies are represented by structural and textural changes recently reviewed by Field and Scott Smith, (1998). These textural changes have strong controls on physical properties such as density, electrical resistivity, polarization and seismic velocity. It can be expected therefore that there will be close agreement between the petrophysics and the kimberlite facies. Geochemical and mineralogical variation have a closer association with properties such as magnetic, electrical conductivity, polarization and gamma radiation. Through these physical properties there is more to be learned about the genesis of the intrusive.

When reviewing physical properties, there are other external influences that must be considered, such as weathering, ground water, salinity and climate. The electrical response of a Botswana kimberlite beneath saline ground water can be expected to be quite different to a Siberian pipe in a region of permafrost. Surprisingly differences due to these external controls are often only small.

A geophysical signature is a measure of the change in physical properties between two localities. So for a complete understanding of the anomalies of kimberlites the character of host rocks as well as internal structures such cross cutting intrusives, rafts of crustal rocks, and of course the wide range of lithospheric xenoliths are required. Due to the regional dependence of these properties they are not covered in this discussion.

\section{KIMBERLITE PHYSICAL PROPERTIES}

\section{MAGNETIZATION}

There is still confusion in the literature about the nature of magnetic mineralogy in kimberlites. Down hole susceptibility logs routinely measure susceptibilities that have large ranges over short distances. E Kostlin has recorded susceptibilities of 3000 samples from 131 African kimberlites. The range for all types were between 50 and $4000 * 10-5$ SI. A study by Clark and French (1990) for DeBeers combined magnetic measurements with petrographic examination and electron microprobe analysis of 33 southern African kimberlites. Some of the more consistent and noteworthy observations from this report are summarized below.

The magnetization of most kimberlites irrespective of classification or age is dominated by remenance.

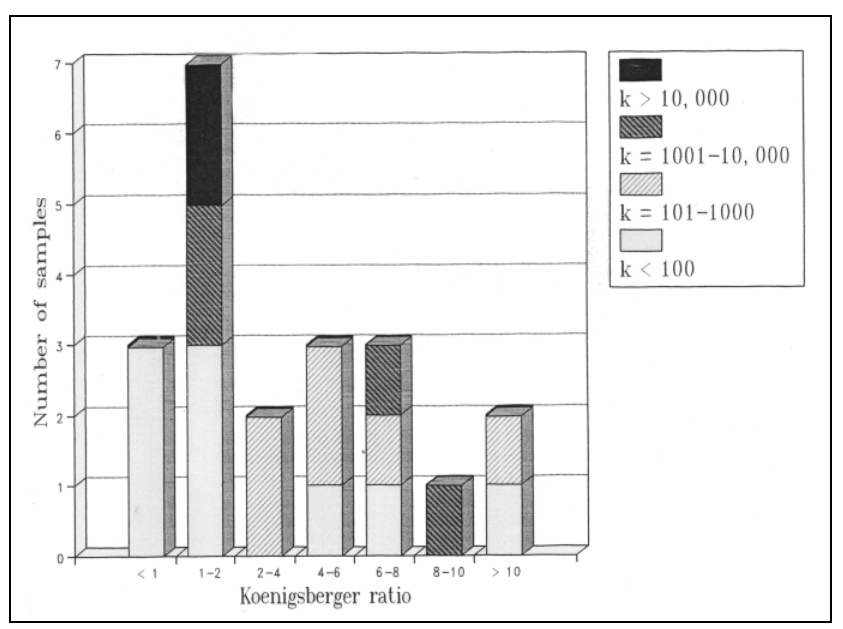

Figure 1 Remenant magnetization represented as a histogram of Koeningsberg Ratio and susceptibility. Based on 30 samples from southern African mined kimberlites. Clark (1990). Values of 1 and higher have a remenant field stronger than the induced field.

Other palaeomagnetic studies in Russia, Africa, Australia and Canada confirm that the Koeningsberg 
ratio is greater than 1 for the majority of pipes. In the Clark study, Kimberlite remenance was found to be stable and in a single direction. Forming at the time of emplacement in very fine grained magnetically hard spinels with high Curie temperatures. With the dominance of magnetic remenance it is not surprising that in exploration, modeling of magnetic anomalies based only on susceptibility give errors in both location and geometry of the kimberlite. This gets worse with increasing age of the pipe; the older remenant field at emplacement increasingly misaligned with the current Earth's Field as the continents move.

The distribution of the magnetic minerals in a kimberlite pipe is primarily in the hypabyssal facies. The transitional and diatreme facies usually have much lower percentages of fine grained oxide minerals.

The magnetic mineralogy of kimberlites with moderately and strongly susceptibilities are dominated by spinels of two compositional ranges from pure magnetite to Mg-titanomagnetites or magnetite to magnesioferrite-rich (Ti)-Mg-titanomagnetites. These mineral phases can be identified by their Curie temperatures during susceptibility-temperature analyses. The wide range of magnetic spinel phases is a characteristic specific to kimberlites.

Kimberlites with lower susceptibility are not absent of oxide phases but instead carry paramagnetic mineral phases.

Primary end member magnetite occurs as primary groundmass grains, suggesting secondary magnetite from serpentinization does not influence the magnetic properties. This has also been observed for Brazilian pipes and was noted in the Kostlin study where susceptibilities of very deep unweathered mine samples did not differ from shallower weathered samples.

In the study, the magnetization of a kimberlite appears to relate to the degree of differentiation of the kimberlite magma. The more highly evolved kimberlites contained spinels that have progressed along magmatic trends towards strongly magnetic compositions. From the samples, the highest susceptibilities observed were the most differentiated calcite kimberlites, Premier and Wesselton.

Sulphides did not contribute to the magnetization of any of the samples. Sulphides were present but were dominantly nickeliferous phases and pyrite. However a pyrite rich, weakly magnetic sample from North Loxtondal, on heating produced monoclinic pyrrhotite significantly increasing its susceptibility. This would suggest that the susceptibility of sulphide bearing kimberlites can be enhanced if heated. This can be a characteristic of Siberian kimberlites, such as the sulphide bearing Krasnopresnenskaya pipe which is cut by a basalt sill at $200 \mathrm{~m}$ depth (Figure 3 ).

\section{DENSITY}

Comparisons of density with kimberlite facies are not commonly reported. Available data indicate a global similarity in distribution of density values. A suitable overview is provided Siberian kimberlites. They have a range of $2.2 \mathrm{gm} / \mathrm{cc}$ to $2.4 \mathrm{~g} / \mathrm{cc}$ for kimberlitic breccias, reducing to a low $1.8 \mathrm{gm} / \mathrm{cc}$ if weathered. Their hypabyssal kimberlite range can be as low as 2.4 but often increase up to $2.9 \mathrm{gm} / \mathrm{cc}$. The lowest densities of $1.4 \mathrm{gm} / \mathrm{cc}$ are associated with crater facies such as pyroclastic tuff. The tuff has a porosity of 30 to 50 percent compared to the 14 to 18 percent of the breccia. For comparison, the Finsch mine in southern Africa has densities mapped at the $100 \mathrm{~m}$ level in two ranges, either 2.4 to 2.6 or 2.6 to $2.8 \mathrm{gm} / \mathrm{cc}$. The lower densities associated with the more fragmented textures.

The global uniformity of kimberlite density and its inverse relation to porosity are reasons why the new technology of airborne gravity gradiometry, Dyke (2002) makes an effective reconnaissance tool for the detection and discrimination of well preserved kimberlites under shallow cover.

\section{ELECTRICAL}

Electrical conductivity and its inverse value resistivity is a property that can be measured by a diverse range of geophysical techniques. Many of the electrical and electromagnetic methods have been applied to kimberlites. Resistivity is closely dependent on the frequency of the measuring signal and in some studies such as Complex or Spectral resistivity attempts have been made to utilize the nature of this frequency dependency for mineral discrimination. As with density, it is often the more fragmented diatreme and crater facies that have the lowest resistivities. Water especial when saline or frozen can also make marked changes to the resistivity values. However unlike density, the resistivities also vary strongly with only minor changes in mineralogy such as clay, sulphides, oxide minerals and graphite. The lowest DC resistivities are always recorded in the shallower more weathered kimberlite. They can be as low as 5ohm-m.

For Siberian kimberlites the full resistivity range is 22 to $800 \mathrm{ohm}-\mathrm{m}$. However the affect of freezing a kimberlite in the permafrost can almost double the resistivity values. 
A DC resistivity tomography survey in BK9, a kimberlite in the Orapa group demonstrates how kimberlites can be mapped in 2D and 3D from downhole measurements, figure 2 . The hypabyssal kimberlite resistivities range between 100 to $250 \mathrm{ohm}-$ $\mathrm{m}$ and the TKB between 20 to $50 \mathrm{ohm}-\mathrm{m}$.

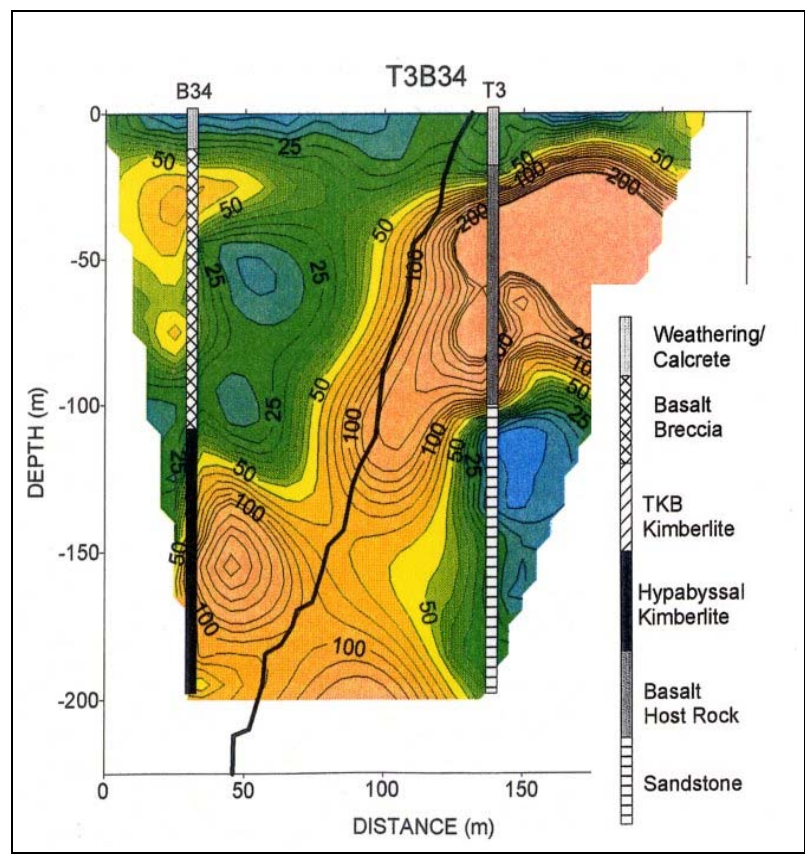

Figure 2. 2D resistivity tomography of kimberlite BK9, Botswana. Source: DeBeers, 1998.

Closely associated with DC resistivity is induced polarization, the ability of a geological body to hold an electrical charge. Minerals that can contribute to this in a kimberlite include sulphides, clays, magnetite and ilmenite. Combined with magnetics induced polarization offers a useful but underdeveloped mapping tool. Samples measured in the laboratory from Siberian kimberlites which are known for their high sulphide content have response times between 1 to 80 milliseconds. This response is not noticeably influenced by low ground temperatures.

Zonge Engineering completed a suite of their electrical and electromagnetic surveys over Siberian pipes for Rio Tinto. Figure 3 shows the resistivity and IP phase angle model sections for the Krasnopresnenskya Kimberlite in Siberia. This pipe is located beneath post Devonian sediments and is cut by a basalt sill between 200 and
300 meters. The resistivity maps the kimberlite and identifies anomalous an IP region in the AKB.

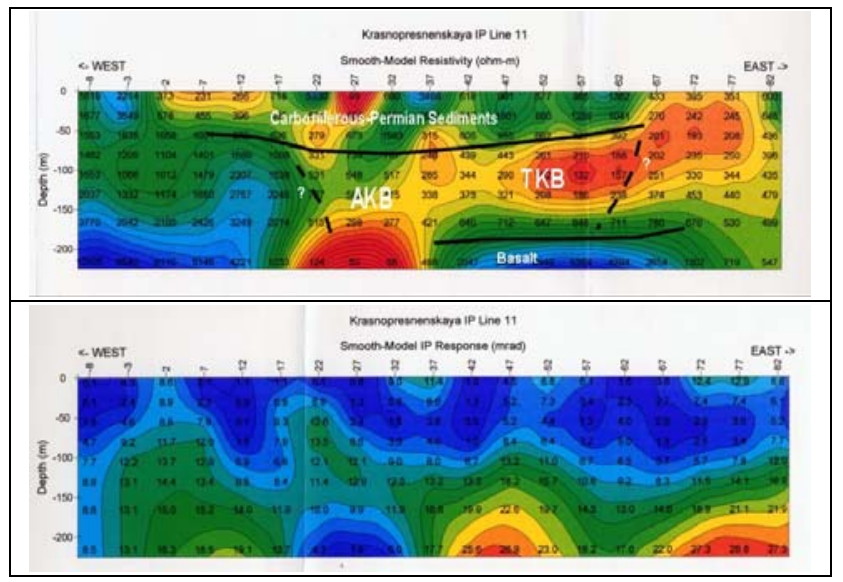

Figure 3. 2D smooth model inversion of a $100 \mathrm{~m}$ dipole IP line across Krasnopresnenskaya Kimberlite Pipe, Siberia. Geological contacts are only approximate. Source: E v Reed (1995).

\section{SEISMIC VELOCITY}

Unlike the other properties, seismic velocities in a kimberlite can have significant regional variations. For example the Jwaneng group of pipes average at 3.85 $\mathrm{km} / \mathrm{s}$ for weathered diatreme kimberlite and $4.88 \mathrm{~km} / \mathrm{s}$ for fresh hypabyssal kimberlite. In contrast the averages for the Kimberely region are 1.48 and 3.10 respectively. Average velocities reported for Siberian kimberlites are hypabyssal $3.0 \mathrm{~km} / \mathrm{s}$ to $4.0 \mathrm{~km} / \mathrm{s}$; Diatreme (TKB) 2.5 to $3.5 \mathrm{~km} / \mathrm{s}$; Crater facies 2.0 to $2.4 \mathrm{~km} / \mathrm{s}$. Seismic surveys are a tool with considerable potential for outlining pipes but still remains under developed because of the high cost and lack of information on rheological properties.

\section{GAMMA RADIATION}

Kimberlites do not have significant levels of radiogenic elements for the purposes of detection by geophysical surveys. The total count levels from 200 hand samples of kimberlites from around the world ranged between 10 and 600 , with an average between 100 to $200 \mathrm{cps}$. The higher values were associated with the more potassic Lamproites and Group II kimberlites. Sometimes signatures are not always what the appear. A strong radiometric response was observed for some of the Juina pipes in Brazil. This was established to be a result of residual radiogenic sediments remaining in the top of the pipes after the original sedimentary cover had been eroded away. 


\section{SUMMARY}

The most important criteria in the future petrophysical analysis of kimberlites is that different properties are attributable to different facies and mineralogies within the kimberlite. Some, such as the magnetic and electrical mineralogy have potential for mapping the internal structures of a pipe and may provide information on the genesis of the pipe. Globally the physical properties are remarkably consistent for each variety of kimberlite. Required are more collaborative studies by the geophysicists, mineralogists and petrologists.

DeBeers and Rio Tinto Mining and Exploration Ltd are thanked for technical contributions in this paper.

\section{REFERENCES}

Clark, DA, and French DH; CSIRO(1990): Rock magnetism and magnetic petrology of kimberlites. Technical report for DeBeers.

Dyke, AL, Harman, P, Mahanta, AM; Preview 99 (2002): Falcon spreads its wings, pp25-28

Field, M, and Scott Smith BH; EA (1998): Textural and genetic classification schemes for kimberlites: A new perspective; Seventh International Kimberlite Conference, Cape Town, pp. 214-216.

Reed, V, Maudlin, C; Technical Report (1995) Russian Geophysical Diamond Project, Technical report for Rio Tinto Mining \& Exploration Ltd.

Contact: FW Arnott; 43 Hendred Way, Abingdon,

Oxfordshire, OX14 2AW, UK, E-mail: frank@arnott-uk.com 